\title{
Investigating the Effect of Near Infra-red \\ Spectroscopy (NIRS) on Early Diagnosis of Cardiac Surgery Associated Acute Kidney Injury
}

Fatemeh Javaherforoosh zadeh ( $\sim \mathrm{f}$ _javaherforoosh@yahoo.com )

Associate Professor of Anesthesia, Department of anesthesia, Ahvaz Anesthesiology and Pain Research Centre, Ahvaz Jundishapur University of Medical Sciences, Ahvaz, Iran https://orcid.org/0000-00027687-5888

\section{Hojatolah Bhandori}

Ahvaz Jondishapour University of Medical Sciences

\section{Sara Jarirahmadi}

Ahvaz Jundishapur University: Ahvaz Jondishapour University of Medical Sciences

\section{Nima Bakhtiari}

Ahvaz Jondishapour University of Medical Sciences

\section{Research article}

Keywords: Near Infra-red Spectroscopy, Kidney Oxygen Saturation, CSA-AKI

Posted Date: September 23rd, 2020

DOI: https://doi.org/10.21203/rs.3.rs-78250/v1

License: (9) This work is licensed under a Creative Commons Attribution 4.0 International License. Read Full License 


\section{Abstract}

Background. Cardiac surgery-associated acute kidney injury (CSA - AKI), is a major complication of cardiac surgery. Early detection of this complication can improve the quality of post-operative care and help to prevent this phenomenon.

Materials and Methods: 148 patients were enrolled to study and 107 patients were selected for analysis between February and September 2019 in the cardiac surgery unit of Golestan Hospital. Ahvaz. Iran. Kidney tissue oxygen saturation was measured in multiple definite times during surgery. Hemoglobin, blood urea nitrogen, creatinine, and lactate were measured during and 48 hours after surgery.

Results: Forty-one patients were diagnosed of CSA-AKI according to KDIGO criteria. Parametric and nonparametric analyzes significant difference was not detected between CSA-AKI and NON CSA-AKI group in the demographic parameter. Repeated measurement of ANOVA Analysis did not show any significant difference in parameters except for BUN. Repeated measurement of ANOVA showed a significant difference in both groups and time factors $(p<0.001, p=0.0006$ respectively). ROC curve analyzes showed in a single point of time, difference the middle of CPB time from baseline high-value in the prediction of AKI 0.764 (0.57 to 0.951) (AUC-CI).

Conclusion; Kidney saturation monitoring could be considered as routine monitoring in cardiac surgery for the rapid detection of CSA -AKI. Although kidney tissue saturation is not correlated directly to the arterial saturation of oxygen, physician and surgery team could predict the chance of acute kidney injury exposure.

\section{Introduction}

Cardiac surgery and its complications have negative impacts on kidney function and can be lead to acute kidney injury and it is associated with increased mortality and morbidity(1). Multiple factors including pre-, intra-, and post-cardiac surgery make kidney susceptible to injury which is known as cardiac surgeryassociated acute kidney injury (CSA-AKI). There are more than 30 different diagnostic criteria for CSA-AKI such as RIFLE, KDIGO, AKIN, and so on resulting in a different range of CSA-AKI incidence, up to $30 \%$ in literature (2). Recently, new CSA-AKI marker such as Neutrophil Gelatinase-associated Lipocalin (NGAL) has been discovered, but common criteria for diagnosis are still based on the increase of plasma creatinine level (3). Causes and pathway of induction of CSA-AKI according to pathophysiology are different, including age, CPB time, cross-clamp time, type of operation, toxins, metabolic factor, ischemia and reperfusion, neurohormonal activation, inflammation and oxidative stress $(4,5)$. Many efforts have been done to the progress and validation of new predictor scales. However, all of them have limits.

Monitoring of kidney oxygen saturation based on Near-infrared spectroscopy (NIRS) is a new approach in the diagnosis of CSA-AKI before the rise of creatinine (6). Near-infrared spectroscopy (NIRS) is a noninvasive approach for the detection of CSA-AKI, which can continue to measures the difference between oxygenated and deoxygenated hemoglobin in a local tissue zone, and so procurement the 
regional oxygen saturation( $\mathrm{rSo}$ ) (7). This technique is limited by its depth of penetration in tissue. Factors such as bilirubin, amount of skin pigment, and external source of light also affect its response(8). NIRS in cardiac surgery is usually used for monitoring of brain oxygen saturation (bSo2). Brain desaturation during surgery is associated with an increased risk for cognitive dysfunction(9). Numerous studies have revealed an association between brain and somatic NIRS monitoring and serum lactate or mixed venous oxygen saturation (Scv02)and local tissue perfusion $(10,11)$. Kidney oxygen desaturation during surgery can be caused to postoperative AKI(12). The study aimed to investigate the effect of Near Infra-red Spectroscopy (NIRS) on early diagnosis of Cardiac Surgery Associated Acute Kidney Injury.

\section{Material And Methods}

\section{Study Design:}

This study was approved by the Anesthesiology and Pain Research Center, Ahvaz Jundishapur University of Medical Sciences (PAIN-9805), under the supervision of the AJUMS Research Ethical Committee (IR.AJUMS.REC.1398.097). This study was accomplished at the Cardiac Surgery unit of Golestan Hospital. Ahvaz. Iran between February and September 2019. After the approval of the ethics committee of Ahvaz Jundishapur University of Medical Sciences, Written informed consent was collected from the patients. All procedures performed according to the standard of care of the center. Inclusion criteria were: Age of patient between 30 to 75 years, candidate for on-pump cardiac surgery. Exclusion criteria were: a history of renal disease, $\mathrm{BMI}>35, \mathrm{EF}<30 \%$, drug history that directly affects the kidneys like NSAID, electrolytes disturbance, urgent surgery, redo surgery.

CSA-AKI diagnosis was based on KDIGO criteria, (ie, an increase in $\mathrm{SCr}$ by $\geq 0.3 \mathrm{mg} / \mathrm{dL}$ or greater within 48 hours; or an increase in $\mathrm{SCr}$ to $\geq 1.5$ times baseline, within 7 days after surgery) (2).

After arrival at the operation room, standard monitoring including five-lead electrocardiography, pulse oximetry, and arterial line for continuous blood pressure monitoring and blood gases were inserted. The sensors of NIRS were connected on the right and left flank area. Before the induction of anesthesia, $\mathrm{kSO}_{2}$ was recorded as a baseline. A standard anesthesia technique was used for all patients. After induction of general anesthesia, a central venous catheter was introduced. For initiation of cardiopulmonary bypass, $350 \mathrm{u} / \mathrm{kg}$ of heparin was injected for each patient. Heparin dosage was attuned based on goal ACT 450480 second. CPB time and cross-clamp time were recorded. After the CPB was terminated, protamine $(1 \mathrm{mg} / \mathrm{kg})$ was given for the reversal of heparin. CPB , cardiac surgery and postoperative management were standardized for all patients.

After surgery, all the patients were admitted to the cardiovascular ICU, with a standard protocol for sedation, analgesia (propofol $0.5 \mathrm{mg} / \mathrm{kg} / \mathrm{h}$ and morphine sulfate $0.1 \mathrm{mg} / \mathrm{kg} / \mathrm{h}$ ), and management of mechanical ventilation (SIMV mode of ventilation). They were extubated when to found weaning criteria. 


\section{Study Patient:}

148 patients were enrolled to study and according to inclusion criteria 107 patients were selected for analysis, and 41 patients were excluded and of them, 107 patients completed the study. In follow up stage 6 patient was excluded owing to lack of information and finally, 101patients were investigated.

\section{Consort diagram}

\section{Study Variables and measurements:}

Demographic data included age, sex, body mass index, history of diabetes mellitus, hypertension, left ventricle ejection fraction, Euro SCORE, kidney depth, baseline kSo2, preoperative hemoglobin, preoperative $\mathrm{SCr}$, and estimated glomerular filtration rate. Laboratory postoperative parameters were collected during the following stages of the study: ICU admission, 6 hours, 12 hours, 24 hours, and 48 hours postoperatively. The arterial blood gas analysis was measured for all of the measurement points (T0-T48).

The primary outcomewas: postoperative CSA-AKI defined by the KIDGO criteria.

The secondary outcomesincluded: cardiac and non-cardiac complications, such as circulatory arrest, reoperation, sepsis, low cardiac output (cardiac index less than $2.2 \mathrm{~mL} / \mathrm{min} / \mathrm{m} 2$ ), pneumonia, hepatic dysfunction, prolonged mechanical ventilation time (PMV: mechanical ventilation time $>48$ hours), massive transfusion (need to $>10$ units of blood component), mortality, need to RRT (renal replacement therapy), length of ICU stay.

The time points of measurement of kSo2 were: before surgery (T0), immediately after induction of anesthesia (T1), immediately after starting of cardiopulmonary bypass (CPB) (T2), during CPB (T3), immediately after weaning of CPB (T4), immediately ICU admission (T5). Left and right Kidney saturation were measured in T0-T5 by NIRS (INVOS 5100C; Medtronic, Inc, Minneapolis, Minn).

We assess the correlation between kSo2 records with CSA-AKI using the KIDGO criteria (13).

\section{Statistical Analysis:}

The normality of all data was checked by Kolmogorov-Smirnov (K-S), Shapiro-Wilk test, D'Agostino skewness test (14). The parametric and non-parametric correlation was calculated for all analysis variables to each other. The sensitivity and specificity of kSo2 were analyzed by AUC-ROC analysis. Time course DATA was analyzed by RM-ANOVA and non-parametric RM analysis. The frequency of secondary outcomes was examined by the Fisher exact test.

\section{Results}

A total of 41 patients (41.41\%) developed CSA-AKI. The median age was 60 (51-69), and 25 (60.97) were male. 
Demographics, Comorbidities, and intraoperative data are listed in Table 1. We found a significant association between Euro SCOREII $(P=0.036), \mathrm{LVEF}<50 \%, \mathrm{CPB}$ time $(P<0.001)$, Cross clamping time $(P=0.036)$, median MAP during $C P B(P=0.042)$, peak serum lactate $(P=0.049)$, and valvular surgery $(P=0.017)$ with CSA-AKI event.

A history of smoking, diabetes mellitus, hypertension, and dyslipidemia has been associated with an increased risk of CSA-AKI, $P<0.001$.Table1

\section{Kidney saturation analysis}

The trend of changes in Right kidney saturation figure 1Aduring the time has a significant difference but no sig difference between two groups ( $<<0.001, p=0.102$ respectively). The trend of changes left kidney saturation figure 1Bduring time have significant differences but no sig difference between two groups $(p<0.001, p=0.089$ respectively). The trend of changes one side kidney saturation with $\mathrm{SpaO} 2$ figure 1Dhas a significant difference in both during time and difference between two groups $(p<0.001, p<0.001$ respectively). The greatest reduction in $\mathrm{ksO} 2$ was at $\mathrm{T} 3$, which was equivalent to $\mathrm{CPB}$ time.

\section{Hemoglobin, BUN and Creatinine analysis}

The trend of changes $\mathrm{Hb}$ (figre2A), SCr (figure2B), and BUN (figure 2C) have a significant difference between two groups $(p<0.001, p<0.001, p<0.001$ respectively). The longest increase in BUN and creatinine level were at T48 and the lowest hemoglobin level was at this time.

\section{AUC-ROC curve analysis}

ROC curve analysis difference of $\mathrm{kSO}_{2}$ in time middle of $\mathrm{CPB}$ from baseline (figure $3 \mathrm{C}$ ) could predict the risk of CSA-AKI (AUC-ROC, 0.914; $\mathrm{Cl}, 0.863-0.965 ; \mathrm{P}<0.001$ ).

\section{Secondary outcome}

The results of the secondary outcomes showed that patients with CSA-AKI had poorer secondary outcomes, containing of Reoperation ( $P=0.009)$, hepatic dysfunction $(P=0.031)$, Massive transfusion $(P=0.032)$, renal replacement therapy $(R R T)(P=0.005)$, ICU stay $(P<.0 .0001)$.

\section{Discussion}

Early diagnosis of cardiac surgery-associated acute kidney injury by current diagnostic methods is not feasible nor cost-effective. The traditional type of CSA-AKI diagnosis is based on the creatinine rise and is not distinguishable in the golden time of treatment. A fast and plausible approach in CSA-AKI could save many of cardiac surgery patients. Recently, measuring kidney tissue oxygen saturation via NIRS as a novel and non-invasive method has been suggested $(6,15-18)$. 
This study showed that kidney oxygen saturation monitoring has a high value in the diagnosis of CSAAKI. Choosing a definite point of time, namely $\mathrm{T} 1$ was induction time, $\mathrm{T} 2$ was starting CPB, T3 was during $\mathrm{CPB}, \mathrm{T} 4$ was the end of CPB and T5 was ICU admission was based on the pathophysiology of CSA-AKI (4). Although many pathways for induction of CSA-AKI are suggested, our conservative inclusion and exclusion criteria reduced confounding variables in this study such as 1 . Controlling the drug regimen changes and lack drug history that directly affect the kidneys like NSAID 2.Acid and base disturbances.

One of the valuable findings of this study was to define the sensitive and specific point for measurement of kidney saturation. This clinical point was during CPB time. The difference of T3 from baseline could be a good index in diagnosing CSA-AKI.

The study was done in 2018 by loubon et al. showed that $20 \%$ decreases of the baseline In NIRS could be considered as a good index in CSA-AKI diagnosis(19). However decreases of a kSo2 in our study were not like this study due to the single point measurement of kSo2, a difference of T3 from Baseline confirm loubon et al study, and have high sensitivity of dismissal in distinguishing of CSA-AKI. As in loubon study brain tissue saturation has not relation with Kidney tissue saturation and is the reason why we did not assess brain oxygen saturation bought blood oxygen saturation also has not relation with $\mathrm{kSo}$. The only reason that differentiates our study from Valuable a study of Loubon et al. we are looking for decreases from baseline in a definite time and evidence of acute kidney injury. That's means evaluate to Factor Simultaneously. Reperfusion phase after ischemia causes increases of tissue saturation of oxygen but this is the effecting agent in AKI. As we show Middle of CPB time is suitable according to ischemiareperfusion. Although it is not pharmacological approved treatment for CSA-AKI evidence of the effectiveness of Dexmedetomidine, Vasopressin, and some Amino acid Suggested Ref. Each drug affects oxidative stress and inflammation pathway for example dexmedetomidine in Inhibit jak/stat phosphorylation (20).

The result of this study discovered that the higher age (although was not significant) and long CPB timecorrelated to postoperative CSA-AKI. These results are indicated by numerous data indicating that CSAAKI is multifactorial. (21) Age is an independent risk factor for this complication(22).

CPB causes the activation of inflammatory factors. That produces vasomotor changes in the kidney. Therefore, the cardiopulmonary bypass time is longer, more inflammatory reaction will be expected(23)

Moreover, the effect of the type of operation on the occurrence of CSA-AKI is also clear. So that valve surgery and complex surgery associated with an increased risk of this complication. This fact was provided by this study (21).

The incidence of CSA-AKI differs from $7 \%$ to $40 \%$ according to previous studies $(24,25)$. The incidence of postoperative CSA-AKI in this study was $41.41 \%$, these results similar to the presently reported data and this was maybe due to establishing sufficient perfusion pressure and prevent the use of nephrotoxic drugs. As the peak of SCr might be detected up to 
7 days after the operation (rendering to the definition of KDIGO Criteria for CSA-AKI) and the NIRS measurements were only recorded during the interoperation, measurements of the kSo2 provide a limited duration to take quick responses. The main benefit of this new noninvasive technique is rapid and continues response and this is the greatest benefit of NIRS. So this way can help to prevent postoperative CSA-AKI(12).

As shown in Table 2, patients with CSA -AKI had higher rates of Reoperation ( $P=0.009)$, hepatic dysfunction $(P=0.031)$, Massive transfusion $(P=0.032)$, renal replacement therapy $(R R T)(P=0.005)$, ICU stay $(P<.0 .0001)$. These complications may be can due to ischemia and reperfusion injury, and it can cause CSA -AKI. These results were similar to Ortega-Loubon (19).

In multiple animal studies that were induced by ischemia-reperfusion, many factors were involved such as the oxidative stress and inflammation pathway(26). Activation of pro-inflammatory and inflammatory Cytokine Like; TNF-a(27), IL-6 (28), and JAK/STAT (29) phosphorylation pathway (30) (31) are the fundamental reason of development CSA-AKI. Kidney saturation by NIRS to use antioxidant agents could be considered as a future method in the prevention of CSA -AKI.

\section{Study limitations}

The major limitation of this study was the small size of samples. This small size is depended on the conservative inclusion criteria of this study. We suggest a large multicenter study with a heterogeneous population. The second limitation was the lack of NIRS monitoring in ICU. It is also recommended for further study.

\section{Conclusions}

Kidney saturation monitoring could be considered as routine monitoring in cardiac surgery for the rapid detection of CSA -AKI. Although kidney tissue saturation is not correlated directly to the arterial saturation of oxygen, the physician and surgery team could predict the chance of AKI exposure.

\section{List Of Abbreviations}

NIRS :Near Infra-red Spectroscopy ; CSA - AKI: Cardiac surgery-associated acute kidney injury; KDIGO: Kidney Disease Improving Global Outcomes; bSo2:brain oxygen saturation ; CPB: Cardio Pulmonary Bypass; RRT: renal replacement therapy

\section{Declarations}

Conflicting Interest: There is no conflict of interest to be declared.

Funding: Financial support for this study was provided by Ahvaz Jundishapur University of Medical Sciences. 
Ethics approval: This paper was part of a thesis Ethics code: (IR.AJUMS.REC.1398.097).

Consent to participate written informed consent signed by all of the patients

Consent for publication: authors provide formal written consent to publish before publication

Availability of data and material: all data were retrieved from the institutional database and are available from the corresponding authors upon reasonable request.

AUTHORS' CONTRIBUTION: F.JZ contributed in concept, study design, the definition of intellectual content; H.B collected data; F.JZ drafted the manuscript. S.J; provided study materials and patients' information. N.B; conceived of the study and participated in its design. All authors read and approved the final manuscript.

\section{Acknowledgment}

This study was done under the support of the Pain Research Center, Ahvaz Jundishapur University of Medical Sciences, Ahvaz, Iran (grant No \#PAIN-9805). A special thanks to From Imam Khomeini Clinical Research and Development unit For Scientific Support of This Research.

\section{References}

1. Wang Y, Bellomo R. Cardiac surgery-associated acute kidney injury: risk factors, pathophysiology and treatment. Nature Reviews Nephrology. 2017;13(11):697.

2. Vives M, Hernandez A, Parramon F, Estanyol N, Pardina B, Munoz A, et al. Acute kidney injury after cardiac surgery: prevalence, impact and management challenges. Int J Nephrol Renovasc Dis. 2019;12:153-66.

3. Hoste EA, Cruz DN, Davenport A, Mehta RL, Piccinni P, Tetta C, et al. The epidemiology of cardiac surgery-associated acute kidney injury. Int J Artif Organs. 2008;31(2):158-65.

4. Bellomo R, Auriemma S, Fabbri A, D'Onofrio A, Katz N, McCullough P, et al. The pathophysiology of cardiac surgery-associated acute kidney injury (CSA-AKI). The International journal of artificial organs. 2008;31(2):166-78.

5. Zadeh FJ, Moadeli M, Soltanzadeh M, Janatmakan F. Effect of Remote Ischemic Preconditioning on Troponin I in CABG. Anesthesiology and Pain Medicine. 2017;7(4).

6. Ortega-Loubon C, Fernandez-Molina M, Fierro I, Jorge-Monjas P, Carrascal Y, Gomez-Herreras JI, et al. Postoperative kidney oxygen saturation as a novel marker for acute kidney injury after adult cardiac surgery. J Thorac Cardiovasc Surg. 2019;157(6):2340-51 e3.

7. Buratto E, Horton S, Konstantinov IE. So near, yet so far: Is isolated cerebral near-infrared spectroscopy in neonates nearly as useful as it is noninvasive? J Thorac Cardiovasc Surg. 2017;154(3):1054. 
8. Biedrzycka A, Lango R. Tissue oximetry in anaesthesia and intensive care. Anaesthesiology intensive therapy. 2016;48(1):41-8.

9. Slater JP, Guarino T, Stack J, Vinod K, Bustami RT, Brown III JM, et al. Cerebral oxygen desaturation predicts cognitive decline and longer hospital stay after cardiac surgery. The Annals of thoracic surgery. 2009;87(1):36-45.

10. Murkin JM, Arango M. Near-infrared spectroscopy as an index of brain and tissue oxygenation. British journal of anaesthesia. 2009;103(suppl_1):i3-i13.

11. Hanson SJ, Berens RJ, Havens PL, Kim MK, Hoffman GM. Effect of volume resuscitation on regional perfusion in dehydrated pediatric patients as measured by two-site near-infrared spectroscopy. Pediatric emergency care. 2009;25(3):150-3.

12. Choi D-K, Kim W-J, Chin J-H, Lee E-H, Hahm KD, Sim JY, et al. Intraoperative renal regional oxygen desaturation can be a predictor for acute kidney injury after cardiac surgery. Journal of cardiothoracic and vascular anesthesia. 2014;28(3):564-71.

13. Abadeer Al, Kurlansky P, Chiuzan C, Truby L, Radhakrishnan J, Garan R, et al. Importance of stratifying acute kidney injury in cardiogenic shock resuscitated with mechanical circulatory support therapy. J Thorac Cardiovasc Surg. 2017;154(3):856-64. e4.

14. Ghasemi A, ZahediasI S. Normality tests for statistical analysis: a guide for non-statisticians. Int J Endocrinol Metab. 2012;10(2):486-9.

15. Ortega-Loubon C, Fernandez-Molina M, Jorge-Monjas P, Fierro I, Herrera-Calvo G, Tamayo E. The Relevance of Renal Oxygen Saturation Over Other Markers in Cardiac Surgery-Associated Acute Kidney Injury. J Cardiothorac Vasc Anesth. 2019;33(10):2622-3.

16. Ortega-Loubon C, Fierro I, Tamayo E. Should kidney oxygen saturation be monitored to prevent acute kidney injury after adult cardiac surgery? J Thorac Cardiovasc Surg. 2019;158(3):e105-e6.

17. Ortega-Loubon C, Herrera-Gomez F, Bernuy-Guevara C, Jorge-Monjas P, Ochoa-Sangrador C, Bustamante-Munguira J, et al. Near-Infrared Spectroscopy Monitoring in Cardiac and Noncardiac Surgery: Pairwise and Network Meta-Analyses. J Clin Med. 2019;8(12).

18. Ortega-Loubon C, Jorge-Monjas P, Tamayo E. Acute kidney injury after adult cardiac surgery: Trying to find the magic gun. J Thorac Cardiovasc Surg. 2019.

19. Ortega-Loubon C, Fernández-Molina M, Fierro I, Jorge-Monjas P, Carrascal Y, Gómez-Herreras Jl, et al. Postoperative kidney oxygen saturation as a novel marker for acute kidney injury after adult cardiac surgery. J Thorac Cardiovasc Surg. 2019;157(6):2340-51. e3.

20. Gu J, Sun P, Zhao H, Watts HR, Sanders RD, Terrando N, et al. Dexmedetomidine provides renoprotection against ischemia-reperfusion injury in mice. Crit Care. 2011;15(3):R153.

21. Saydy N, Mazine A, Stevens L-M, Jeamart H, Demers P, Pagé $P$, et al. Differences and similarities in risk factors for postoperative acute kidney injury between younger and older adults undergoing cardiac surgery. J Thorac Cardiovasc Surg. 2018;155(1):256-65.

22. Chen S-W, Chang C-H, Fan P-C, Chen Y-C, Chu P-H, Chen T-H, et al. Comparison of contemporary preoperative risk models at predicting acute kidney injury after isolated coronary artery bypass 
grafting: a retrospective cohort study. BMJ open. 2016;6(6):e010176.

23. Jorge-Monjas P, Bustamante-Munguira J, Lorenzo M, Heredia-Rodríguez M, Fierro I, Gómez-Sánchez $E$, et al. Predicting cardiac surgery-associated acute kidney injury: the CRATE score. Journal of critical care. 2016;31(1):130-8.

24. Machado MN, Nakazone MA, Maia LN. Prognostic value of acute kidney injury after cardiac surgery according to kidney disease: improving global outcomes definition and staging (KDIGO) criteria. PloS one. 2014;9(5).

25. Zou H, Hong Q, Gaosi X. Early versus late initiation of renal replacement therapy impacts mortality in patients with acute kidney injury post cardiac surgery: a meta-analysis. Critical Care. 2017;21(1):150.

26. Furuichi K, Wada T, Yokoyama H, Kobayashi K. Role of Cytokines and Chemokines in Renal IschemiaReperfusion Injury. Drug news \& perspectives. 2002;15(8):477-82.

27. Donnahoo KK, SHAMES BD, HARKEN AH, MELDRUM DR. The role of tumor necrosis factor in renal ischemia-reperfusion injury. The Journal of urology. 1999;162(1):196-203.

28. Patel NS, Chatterjee PK, Di Paola R, Mazzon E, Britti D, De Sarro A, et al. Endogenous interleukin-6 enhances the renal injury, dysfunction, and inflammation caused by ischemia/reperfusion. Journal of Pharmacology and Experimental Therapeutics. 2005;312(3):1170-8.

29. Yang N, Luo M, Li R, Huang Y, Zhang R, Wu Q, et al. Blockage of JAK/STAT signalling attenuates renal ischaemia-reperfusion injury in rats. Nephrology Dialysis Transplantation. 2007;23(1):91-100.

30. Jang HR, Ko GJ, Wasowska BA, Rabb H. The interaction between ischemia-reperfusion and immune responses in the kidney. Journal of Molecular Medicine. 2009;87(9):859-64.

31. Stroo I, Stokman G, Teske GJ, Raven A, Butter LM, Florquin S, et al. Chemokine expression in renal ischemia/reperfusion injury is most profound during the reparative phase. International immunology. 2010;22(6):433-42.

\section{Tables}

Table 1 Operative characteristic and demographic DATA 


\begin{tabular}{|c|c|c|c|c|}
\hline Variables & $\begin{array}{l}\text { Overall } \\
(\mathrm{n}=101)\end{array}$ & CSA-AKI (41) & $\begin{array}{l}\text { Non CSA-AKI } \\
\text { (70) }\end{array}$ & P value \\
\hline \multicolumn{5}{|l|}{ Demographic Data } \\
\hline Age, y, median (IQR) & $59(52-67)$ & $60(51-69)$ & $58(54-64)$ & 0.978 \\
\hline Male & $70(69.30$ & $25(60.97)$ & $45(64.28)$ & 0.838 \\
\hline BMI, $\mathrm{kg} / \mathrm{m}^{2}$ & $27.9( \pm 3.5)$ & $30( \pm 4.3)$ & $27.51( \pm 3.2)$ & 0.199 \\
\hline $\begin{array}{l}\text { Euro SCOREII, Median } \\
\text { (IQR) }\end{array}$ & $1.3(0.8-2)$ & $1.96(1-2.3)$ & $0.95(0.8-2)$ & $0.036^{*}$ \\
\hline \multicolumn{5}{|l|}{ Comorbidities } \\
\hline Smoker & $53(52.47)$ & $37(90.24)$ & $16(22.87)$ & $<0.001 *$ \\
\hline Hypertension & $45(44.54)$ & $36(87.8)$ & $9(12.86)$ & $<0.001 *$ \\
\hline Diabetes mellitus & 56(55.45) & $31(75.61)$ & 25(35.71) & $<0.001 *$ \\
\hline Dyslipidemia & 68(67.32) & 28(68.29) & $30(49.86)$ & $0.011 *$ \\
\hline $\begin{array}{l}\text { Left ventricular dysfunction } \\
\text { (LVEF<50\%) }\end{array}$ & $47(46.53)$ & $32(82.05)$ & 15(21.43) & $<0.001 *$ \\
\hline \multicolumn{5}{|l|}{ Intraoperative data } \\
\hline CPB time, $\min$ & $105.42( \pm 20.13)$ & $135( \pm 15.45)$ & $75.15( \pm 15)$ & $<0.001 *$ \\
\hline Cross clamping time & $80.21( \pm 17.11)$ & $97.11( \pm 12.14)$ & $72.32( \pm 4.32)$ & $0.036 *$ \\
\hline MAP during CPB & $65.32( \pm 15.14)$ & $54.21( \pm 15.15)$ & $65.64( \pm 10.08)$ & $0.042 *$ \\
\hline Peak Lactate level mg/dl & 40.51( \pm 12.11$)$ & $10.75( \pm 4.31)$ & $4.15( \pm 3.12)$ & $0.049 *$ \\
\hline CABG & $71(90.62)$ & $31(75.61)$ & $40(57.11)$ & 0.065 \\
\hline Valve surgery & 21(21.09) & $4(9.76)$ & $21(30)$ & $0.017 *$ \\
\hline CABG + valve & $9(8.91)$ & $6(14.63)$ & $3(4.23)$ & 0.071 \\
\hline
\end{tabular}

IQR, interquartile range; Euro SCOREII, European system for cardiac operative risk evaluation; CPB. Cardiopulmonary bypass; * Fisher exact test

TABLE 2. Patient postoperative endpoints according to the presence of cardiac surgeryassociated acute kidney injury

Variables

\begin{tabular}{lllll}
\hline Variables & $\mathbf{N}(\%)$ & Non-CSA-AKI(70) & AKI(41) & P value \\
\hline Reoperation & $20(19.80)$ & $7(10)$ & $13(31.71)$ & $0.009^{*}$ \\
& & & & \\
\hline Delirium & $9(8.91)$ & $3(6.29)$ & $6(14.63)$ & 0.073 \\
\hline Sepsis & $7(6.93)$ & $2(2.86)$ & $5(12.20)$ & 0.098 \\
\hline Infection & $7(6.93)$ & $2(2.86)$ & $5(12.20)$ & 0.098 \\
\hline Dysrhythmia & $9(8.9)$ & $5(7.14)$ & $4(9.76)$ & 0.723 \\
\hline Circulatory arrest & $4(3.96)$ & $2(2.86)$ & $2(4.88)$ & 0.625 \\
\hline Low cardiac output & $12(11.88)$ & $7(12.20)$ & $5(10)$ & 0.757 \\
\hline Pneumonia & $1(0.99)$ & 0 & $1(2.4)$ & 0.369 \\
\hline PMV & $11(10.89)$ & $2(2.86)$ & $9(21.95)$ & $0.002^{*}$ \\
\hline Hepatic dysfunction & $18(17.82)$ & $7(10)$ & $11(26.83)$ & $0.031^{*}$ \\
\hline Massive transfusion & $41(40.59)$ & $16(22.86)$ & $18(43.90)$ & $0.032^{*}$ \\
\hline RRT & $5(12.2)$ & $5(12.2)$ & 0 & $0.005^{*}$ \\
\hline 30-d mortality & $10(9.9)$ & $5(7.14)$ & $5(12.20)$ & 0.494 \\
\hline ICU stay, median (IQR) & $7(3-12)$ & $3(2-5)$ & $12(10-15)$ & $<0.0001^{*}$ \\
\hline
\end{tabular}


AKI, Acute kidney injury; PMV, prolonged mechanical ventilation; ICU, intensive care unit; IQR, interquartile range; RRT, Renal replacement therapy. *Fisher exact test.

\section{Figures}
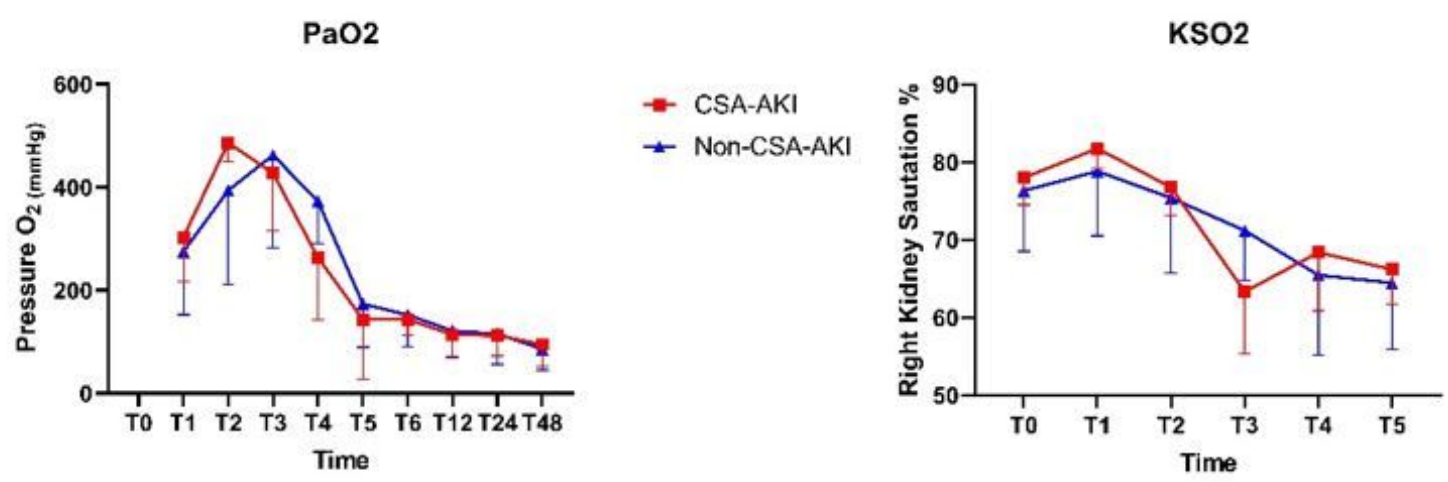

- Right KsO2 in CSA-AKI

- Right KsO2 in Non-CSA-AKI

KSO2
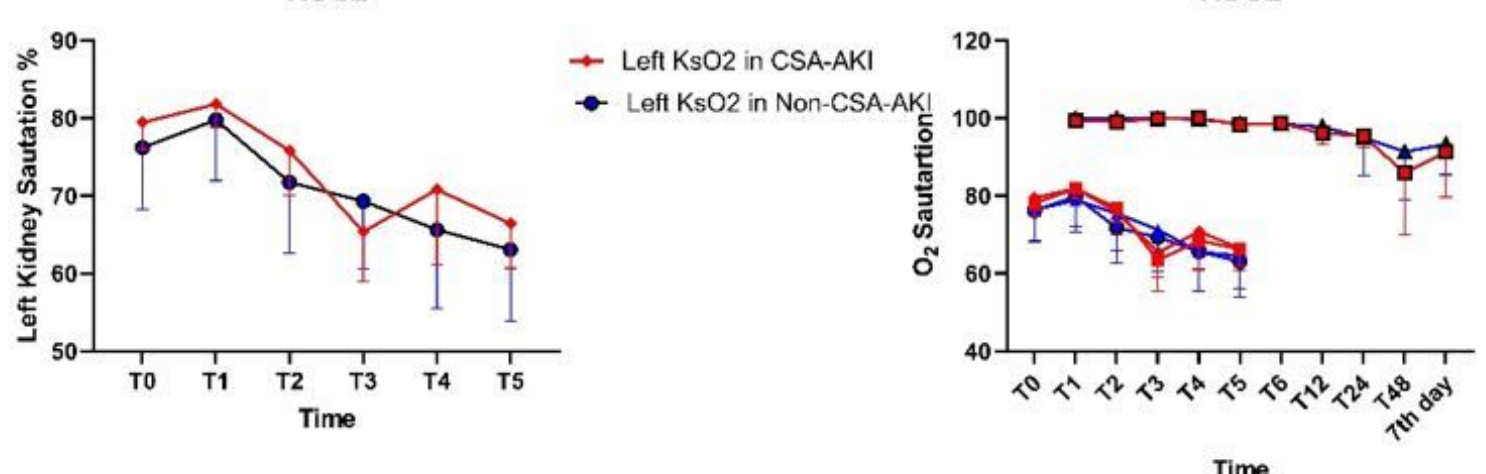

- Right $\mathrm{KsO} 2$ in CSA-AKI

+ Right $\mathrm{KsO} 2$ in

- Non-CSA-AKI

$\rightarrow$ Left KsO2 in CSA-AKI

- Left $\mathrm{KsO} 2$ in Non-CSA-AKI

- $\mathrm{SaO} 2$ in CSA-AKI

- $\mathrm{SaO} 2$

Non-CSA-AKI

Figure 1

Trend of changes of Kidney saturation by NIRS during study 


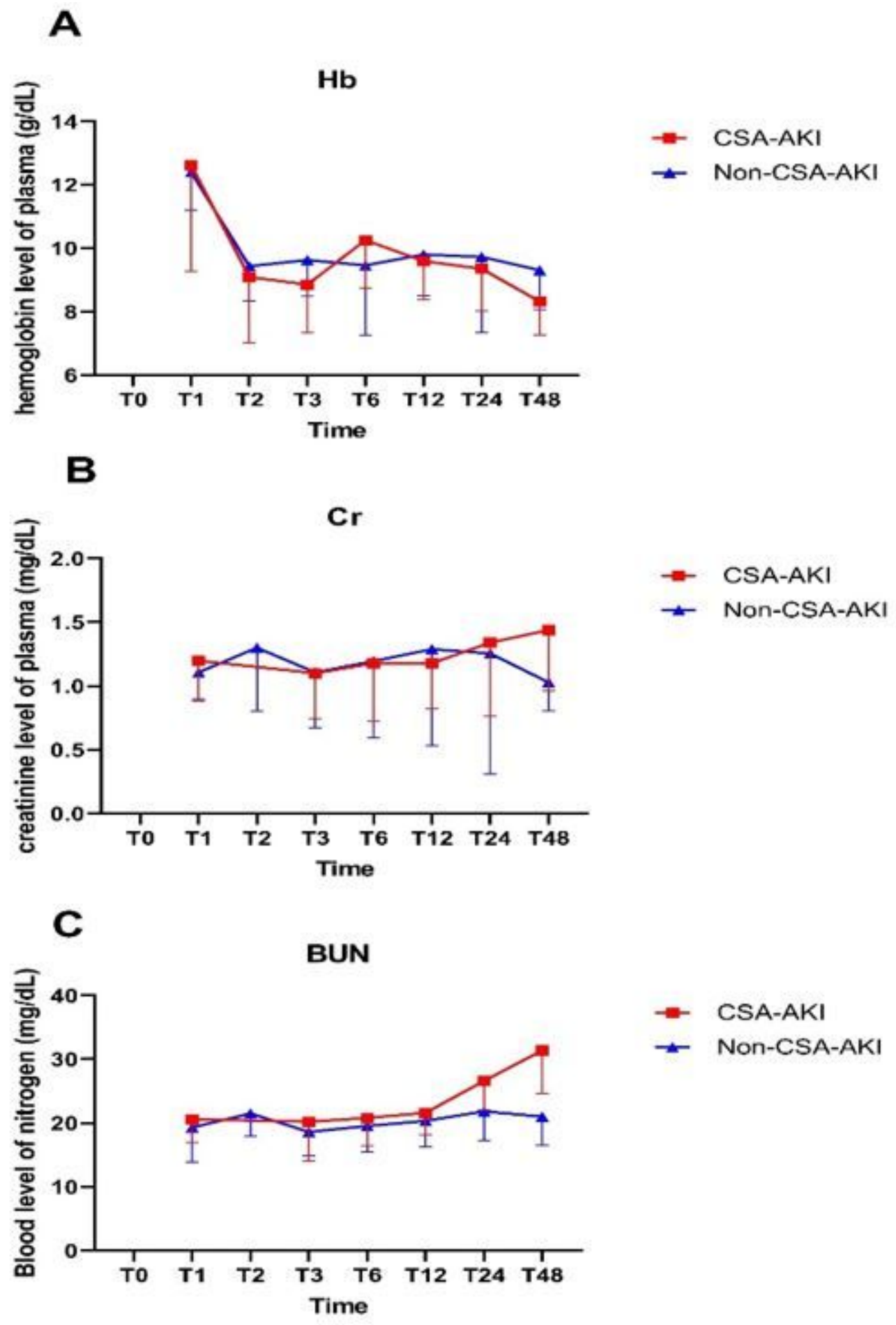

Figure 2

Trend of changes of hemoglobin, creatinine and blood urea nitrogen during study 
A

Difference T1-T0

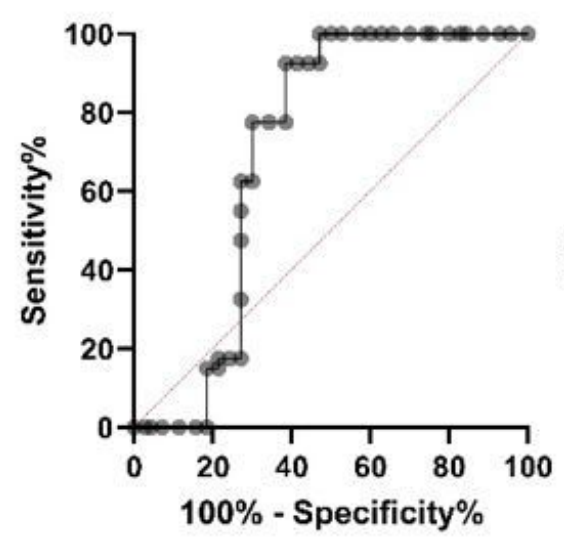

AUC $\mathrm{Cl}(95 \%)$

0.704 (0.607 to 0.801 )
C

ROC curve T3-T0

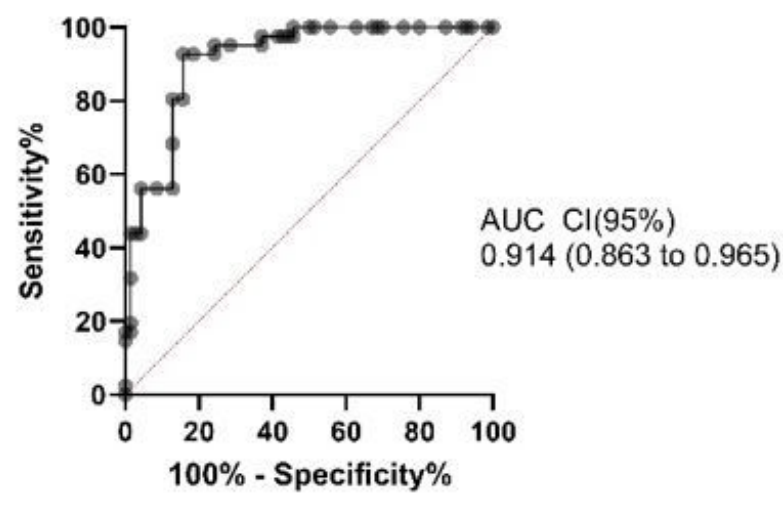

ROC curve T2-T0

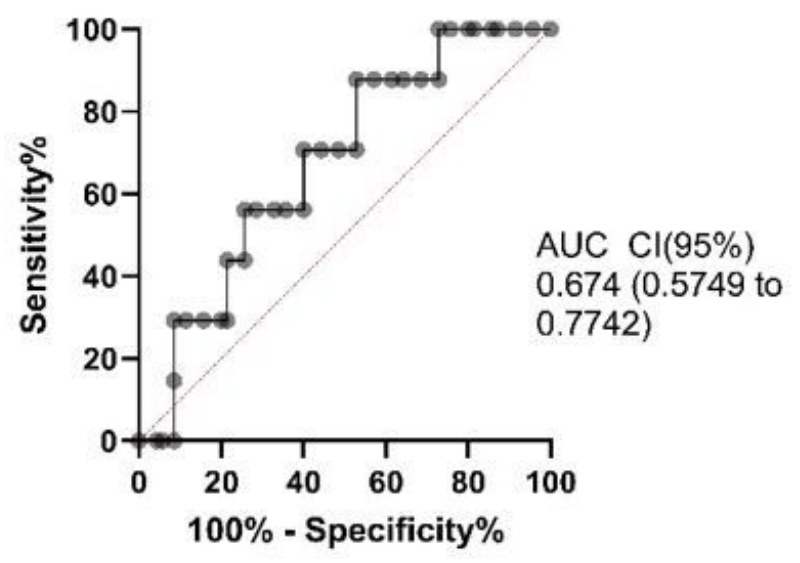

D

ROC curve T4-T0

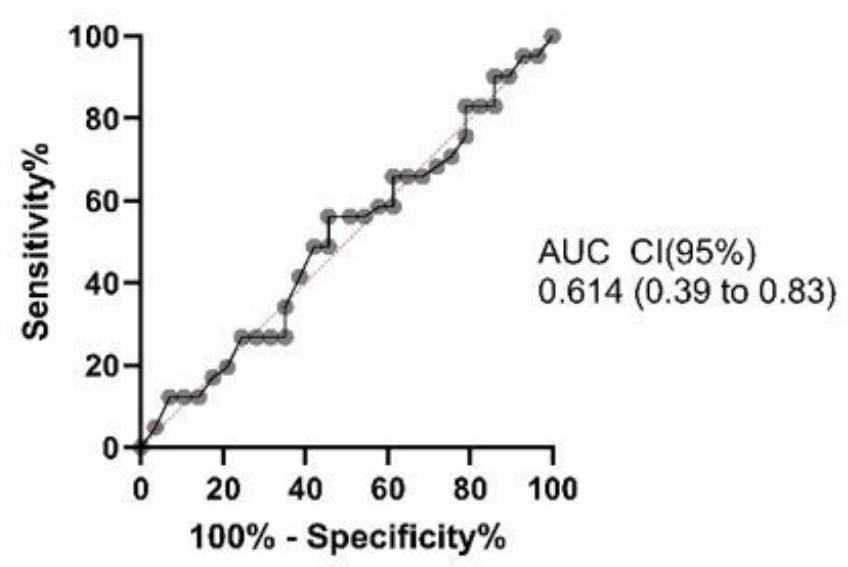

Figure 3

AUC-ROC curve at different time from baseline

\section{Supplementary Files}

This is a list of supplementary files associated with this preprint. Click to download.

- GraphicalAbstract.JPG 